\title{
A review of metallic bridge failure statistics
}

\author{
B.M. Imam \& M.K. Chryssanthopoulos \\ Faculty of Engineering and Physical Sciences, University of Surrey, Guildford, GU2 7XH, UK
}

\begin{abstract}
This paper presents a review of bridge failure statistics, based on literature survey and webbased search, focusing on metallic bridges. Failure cases are distinguished between those resulting in bridge collapse and those that have not reached collapse but resulted in loss of serviceability. Classification of the most common failure causes and modes of failure is undertaken. Statistics regarding the time frame of collapses in the bridge lifetime, bridge structural configuration and the number of resulting casualties are presented. The results show that collapses due to natural hazards, design errors and limited knowledge are the most commonly encountered in metallic bridges, followed by accidents and human error. When analysed chronologically, the data demonstrates a decreasing trend for collapses attributed to limited knowledge and an increasing trend in failures resulting from accidents and natural hazards. In terms of non-collapse cases, fatigue failures are found to be predominant. The paper concludes with a discussion of bridge failure consequences and their significance in risk assessment of bridge structures.
\end{abstract}

\section{INTRODUCTION}

Studying the failures of the past can be useful in mitigating the incidence and potential of future failures. A first step towards the understanding and quantification of the risk of failure of bridges can be provided by acquiring knowledge on the failure mechanisms of existing structures and the root of causes of collapse. Studies aimed independently for different types of bridges, in terms of their material and form, may lead to the identification of predominant failure causes and modes for each bridge type. Clearly, trends picked up through statistical analysis can aid in identifying and understanding the potential of the most significant hazards affecting bridge structures and help in planning against their consequences. Such studies are restricted by the fact that many partial failures are not reported publicly and even amongst those that are, many have not been examined in sufficient detail. Nevertheless, over the last decades, engineers have realised the importance of collecting and archiving information regarding structural failures and have attempted to review this information in a collective manner.

One of the largest databases of bridge failures has been established by Imhof as part of his $\mathrm{PhD}$ thesis (Imhof 2004). It contains 347 cases during the period between 1813 and 2004 and comprises road as well as railway and pedestrian bridges. The statistics in his database have shown that natural hazards to- gether with ship and vehicle impacts make the largest contribution to the actual collapses. Flooding, scour and earthquakes were found to be on top of the list in terms of natural hazards. This database has now been updated by incorporating the latest incidents from 2004 onwards and can be easily accessed via the web (Bridge Forum 2009).

Supporting the trends observed in Imhof's database, reviews of bridge failures in the period 19772000 in the USA has similarly revealed vehicle impacts together with flooding and scour as the primary causes of bridge failures (Hadipriono 1985; Hadipriono \& Diaz 1988; Harik et al. 1990; Wardahana \& Hadipriono 2003). A similar review of worldwide bridge failures has shown an analogous trend (Smith 1976; Biezma \& Schanack 2007). A separate analysis of structural failures comparing different types of structures has shown that bridges are one of the riskiest structure types in terms of failure consequences as they resulted in the highest number of deaths and injuries as compared to other types of structures (Eldukair et al. 1991).

Apart from general analyses of bridge failure statistics, there have also been studies focusing on particular cases of bridge collapses in more detail. For example, Sibly \& Walker (1977) present an in-depth review and discussion of the collapses of four metallic bridges caused by design errors. A detailed discussion of a number of bridge failures, their causes and the lessons learned from each of them is pre- 
sented by Ross (1984), Feld \& Carper (1997), Akesson (2008) and Collins (2008).

On the other hand, some studies have concentrated on a specific failure cause and reviewed the resulting bridge collapses. For example, a review of 131 bridge failures in the UK due to scour/flood during the period between 1846-2003 was carried out (JBA Consulting 2004). A similar review of UK bridge collapses due to flood events has also been presented by Reed (2004).

A high proportion of structural failures have occurred as a consequence of human errors in design or construction. Although these are difficult to quantify, there have been attempts in the past to propose methods for taking these into account and analyse their effect on structural reliability (Nowak 1979; Nowak \& Carr 1985; Ellingwood 1987). Criteria by which the proneness to failure of a proposed design may be judged were suggested by Pugsley (1973) and a more mathematical approach was developed by Blockley (1976).

The aim of this paper is to synthesise and classify damage/failure/collapse cases of metallic bridges worldwide from the early $19^{\text {th }}$ century up to the present. A database of 164 failures of metallic bridges extracted from the literature, the web and news reports was compiled. The evaluation of the database is carried out in terms of identifying the factors contributing to the failure or collapse, the modes of failure or collapse as well as an analysis of the structural form of the bridges. Other points which are considered are the construction date and age of the failed bridges and the number of casualties resulting from the failures. The paper concludes with a discussion of the significance of consequence analysis in terms of risk assessment giving some general guidelines on how consequences of bridge failure can be quantified.

\section{ANALYSIS OF FAILURE DATA}

A total of 164 cases of failure of metallic bridges were retrieved from the literature. Of these $53 \%$ were highway bridges, $34 \%$ were railway bridges and a small percentage were footbridges. Of the 164 reported cases, $87(51 \%)$ were classified as 'collapse', $73(47 \%)$ as 'no collapse' and $4(3 \%)$ as unknown. For the purposes of this study, 'collapse' is defined as one or more structural elements falling down from the bridge as a result of the failure rendering the structure incapable of remaining in service. 'No collapse' covers the cases that have resulted in loss of function (such as fatigue cracking which could result in collapse if left unchecked) and have caused bridge closures, repairs or strengthening works. Considering the cases which resulted in collapse, about two third took place while the bridge was in service whereas the remaining one third oc- curred during construction. It should be noted that in compiling the database, cases for which damage/collapse was attributed to earthquake action or wars have been excluded. However, other natural hazards (e.g. flooding, extreme wind) are included.

The processing and statistical representation of the collected data is a complex process which should be undertaken with caution as the causes and different modes of failure are widespread. A systematic classification is essential in order to be instructive and amenable to comparison with preceding studies. In this paper, the causes of failure have been divided into design errors, limited knowledge, natural hazards (excluding earthquakes), human errors, accidents, overloading and corrosion. Design errors include cases where there was evidence of incorrect design assumptions, wrong estimation of loads, oversight of failure modes etc. Limited knowledge captures the cases where there was insufficient understanding of a failure mode, such as aerodynamic instability or a structural/material problem such as brittle fracture, fatigue or buckling. Failures due to limited knowledge usually took place with the introduction of new materials or new forms of design or due to severe extrapolation of what at the time had proved successful. Natural hazards encompass the case where failures have taken place due to extreme loading such as flooding, storms or very high winds. Human errors are distinguished from design errors and cover those failures caused by negligence, ignorance, mistakes in calculations, as well as poor workmanship, wrong assembly sequence, etc. Accidents pertain to vehicle and ship impacts, fire and explosions (excluding war actions, vandalism and terrorist attacks). Bridge failures caused by deterioration are covered by the corrosion category. It should be mentioned here that, in many cases, failure is caused by a combination of causes. In these cases, an attempt has been made to identify as far as possible the primary cause, and to classify the case accordingly. Arguably, another approach would have been to allow multiple causes to be attributed, and to thus examine the relative presence of different adverse factors, regardless of whether they were the main cause of any particular incident. However, there are difficulties with the latter approach, not least the fact that the results would lack the sharpness and focus provided through the former.

\subsection{Collapsed bridges}

The majority of the 87 cases of metallic bridge collapses occurred in the USA (36\%) and UK (20\%), partly due to the large number of such bridges in these countries. The distribution of failure causes for the collapse database is shown in Figure 1. The most important factors (almost equally) contributing to collapse are design errors (22\%), limited knowledge $(22 \%)$ and natural hazards $(21 \%)$; these are followed 


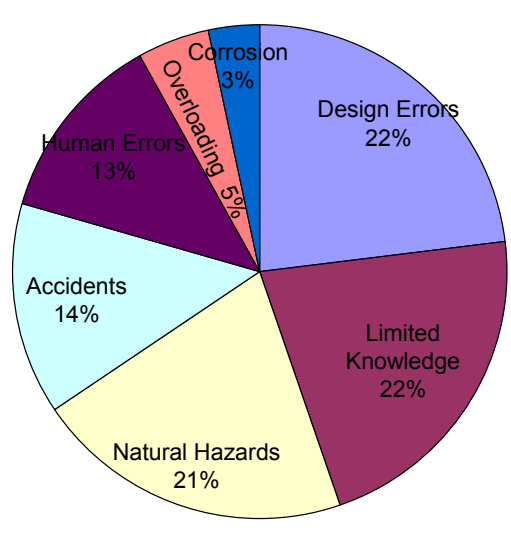

Figure 1. Failure causes leading to collapse of metallic bridges.

by accidents (14\%), human errors (13\%) and overloading $(5 \%)$. Clearly, there is no single dominant cause of collapse for metallic bridges, though the top three amount to almost two thirds of the whole. In contrast, Imhof's analysis for all bridge types revealed the following: natural hazard $(29 \%)$, design errors $(21 \%)$, accidents $(18 \%)$, overloading $(10 \%)$, human errors $(10 \%)$, limited knowledge $(10 \%)$, corrosion $(2 \%)$. An interesting observation is that limited knowledge appears to be a more frequent cause of failure for metallic bridges, as compared to the entire bridge failure database. This could be attributed to the way in which the technology for metallic bridges often moved in spurts, typically related to progress in iron/steel manufacturing and/or assembly, with structural understanding following suite. Natural hazards and design errors are at the top of the list for both databases, although the former cause appears to have a slightly less influence within the metallic bridge subset. Overloading is found to have a less profound effect on metallic bridges as compared to the entire bridge database. It is also interesting to note that only 3 collapses out of $87(3 \%)$ appear to be triggered by corrosion problems, which is also in agreement with Imhof's results, though the quality/detail of the retrieved data may be partly influencing this observation. In other words, deterioration due to corrosion is, more often than not, addressed before it has reached a level at which it is the primary reason for a collapse.

Table 1 attempts to compare failure causes for different time periods. It can be seen that limited knowledge played a major role in the recorded collapses up to the mid-twentieth century. This coincides with periods when fatigue, fracture and buckling were still not fully understood and materials with imprecisely known behaviour were first introduced such as cast and wrought iron and high strength steel. These resulted in 5 bridges which collapsed, in that period, due to fatigue failure, 4 due to buckling of compression members and 4 due to brittle fracture. As Table 1 shows, collapses due to limited knowledge have considerably decreased in re- cent decades with the last being the catastrophic 1970 and 1971 box-girder bridge collapses in Milford Haven, UK, West Gate, Australia and Koblenz, Germany due to buckling effects. Table 1 shows no obvious trend in terms of design errors and human errors, which is an interesting observation, given the emphasis on quality assurance and other human error mitigating procedures introduced in the past thirty years. On the other hand, there appears to be an overall increase in the percentage of bridge collapses due to natural hazards and accidents over the years. The latter can be attributed to the continuous increase in transportation demand, both highway and railway as well as waterway ship traffic, which resulted in a number of vessel impacts to bridges. The increase in bridge collapses due to natural hazards may be attributed, on one hand, to the development of infrastructure in more hazardous terrain, and, on the other, to changing environmental conditions and more extreme weather circumstances observed during the last decades, though it is speculative to suggest that this is linked in some way to climate change effects.

In Table 2, the bridge collapses are divided between those that happened during the construction stage of the bridge and those that took place when the bridge was in service. As previously mentioned, two thirds of the collapses took place while the bridge was in service whereas the remaining one third occurred during construction. Table 2 shows that design and human errors are more common during the construction stage but play a secondary role when compared to natural hazards and accidents for completed bridges.

The distribution of the failures modes for the 87 cases of bridge collapses is shown in Figure 2. It can be seen that for metallic bridges the most frequently encountered modes are scour of piers/foundations $(17 \%)$, buckling $(16 \%)$, fatigue $(13 \%)$, impact $(13 \%)$ and fracture $(9 \%)$. Though scour is an important failure mode for all types of bridges, fatigue and fracture taken in combination appears to be the most critical failure mode for metallic bridges, closely followed by buckling. It should be noted that $14 \%$ of the failure modes are classified as unknown due to insufficient detail in the information provided.

Table 1. Cause of bridge collapses by date of failure.

\begin{tabular}{lrccc}
\hline Collapse cause & Pre-1900 & $1900-1940$ & $1941-1990$ & $1991-$ \\
\hline Limited knowledge & $10(53 \%)$ & $5(36 \%)$ & $4(13 \%)$ & $0(0 \%)$ \\
Design errors & $4(21 \%)$ & $4(29 \%)$ & $7(23 \%)$ & $5(25 \%)$ \\
Natural hazards & $1(5 \%)$ & $3(21 \%)$ & $8(26 \%)$ & $6(30 \%)$ \\
Accidents & $1(5 \%)$ & $1(7 \%)$ & $6(19 \%)$ & $4(20 \%)$ \\
Human errors & $2(11 \%)$ & $1(7 \%)$ & $4(13 \%)$ & $2(10 \%)$ \\
\hline
\end{tabular}


Table 2. Cause of bridge collapses by stage of failure.

\begin{tabular}{lcr}
\hline Collapse cause & During construction & In service \\
\hline Limited knowledge & $5(26 \%)$ & $14(74 \%)$ \\
Design errors & $14(70 \%)$ & $6(30 \%)$ \\
Natural hazards & $0(0 \%)$ & $18(100 \%)$ \\
Accidents & $0(0 \%)$ & $12(100 \%)$ \\
Human errors & $8(73 \%)$ & $3(27 \%)$ \\
\hline
\end{tabular}

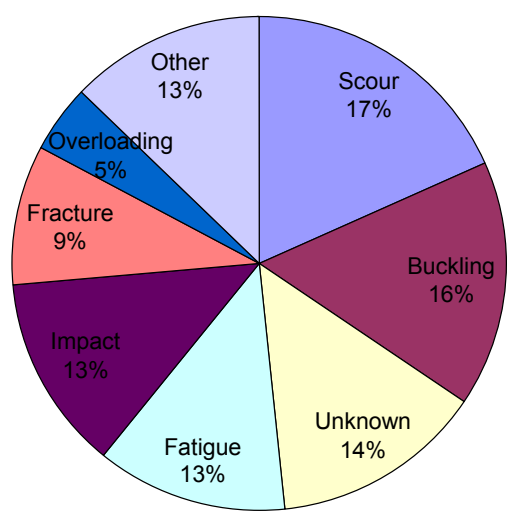

Figure 2. Failure modes leading to collapse of metallic bridges.

From a more detailed analysis of the data pertaining to the collapsed bridges, it was found that almost all collapses (13 out of 14) attributed to buckling took place during the construction stage of the bridge. Buckling was also found to be the most common failure mode associated with design and human errors $(30 \%$ and $36 \%$ of the cases, respectively). Looking at impact, more than half of bridge collapses (6 out of 11) were caused by ship impacts, whereas 16 out of 18 cases of those linked to natural hazards were attributed to flooding, scour and hydraulic effects on the collapsed bridges. Clearly, there is need for more efficient design and assessment of bridges with respect to flood and scour conditions, especially during a period where changing environmental conditions have been established as a critical issue for civil infrastructure in general, and bridge structures in particular.

The distribution of the collapsed metallic bridges with respect to their structural arrangement/form is shown in Figure 3. As can be seen, the majority are truss bridges (35\%) and girder bridges $(21 \%)$, partly due the fact that they comprise the largest fraction of the metallic bridge population. As before, for a noticeable proportion $(15 \%)$, the bridge form has not been clearly reported.

A more detailed analysis reveals that buckling was the primary failure mode for all four collapsed box girder bridges which demonstrates the susceptibility of this type of bridge to the particular failure mode.

The distribution of the reported collapses with respect to the year of construction of the bridges is shown in Figure 4. As can be seen through the two peaks on the histogram, the majority of the bridges that collapsed were constructed in the period 18701910 and 1950-1970. Perhaps this is of no surprise since the first period coincides with the development of railway networks in Europe and North America, and the concomitant widespread use of cast and wrought iron around the world, whereas the second period is closely linked to the introduction of welding technology for bridge construction. Given that a relatively high number of bridges were constructed during these periods, it may be statistically justified that the number of collapses is higher. To answer this question more conclusively, the number of collapsed bridges would have to be normalised through the number of bridges constructed.

Figure 5 shows the distribution of the reported collapses with respect to the year the bridge collapses occurred. On first sight, it would appear that the number of bridge collapses exhibits an increasing trend. However, this should be viewed within the context of the continuous and very considerable increase in the bridge population, as well as the increased tendency for reporting and recording such events. In the same figure, the contribution of each failure cause to the total number of collapses is also presented where it can be clearly seen that the percentage of collapses attributed to natural hazards and accidents has increased over the last decades whereas the contribution of limited knowledge has decreased.

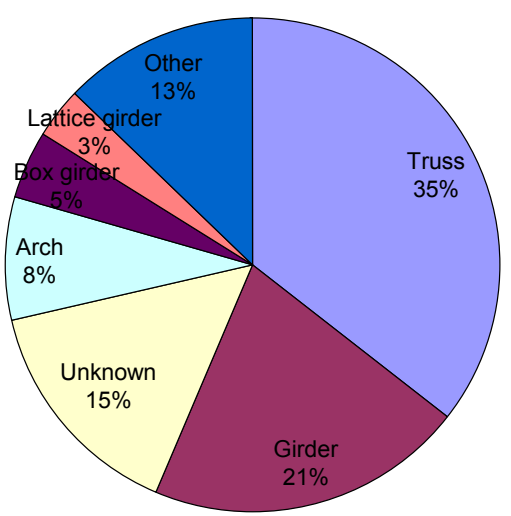

Figure 3. Structural form of collapsed metallic bridges.

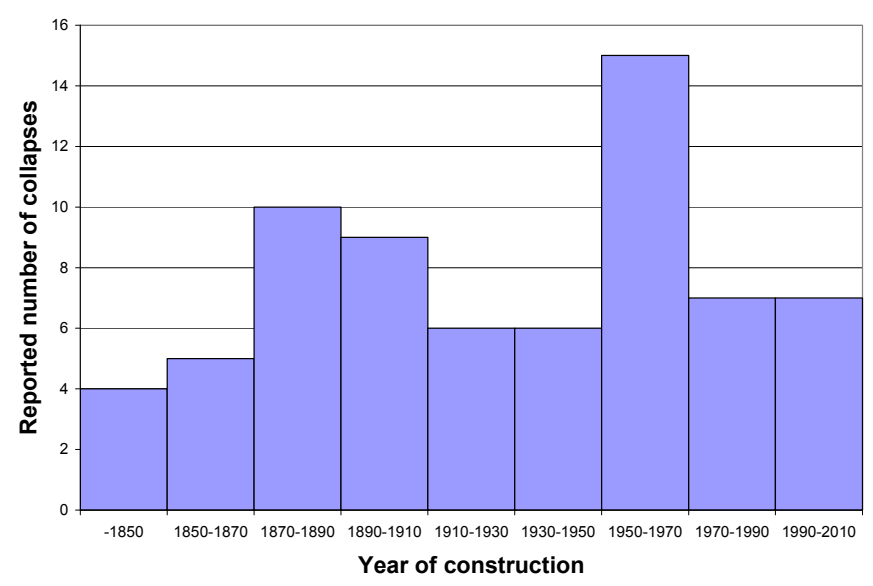

Figure 4. Histogram showing reported collapses with respect to year of construction of the bridges. 
The effect of bridge span on the number of casualties due to collapse was also investigated (see Fig. 6 ) in an attempt to relate a primary bridge design parameter to the consequences of a potential collapse. It could be argued that the longer the bridge span is, the higher the fatalities would be. This can, to some extent, be seen in Figure 6 where collapsed metallic bridges having spans less than $40 \mathrm{~m}$ resulted in zero or less than 10 casualties. However, it can also be seen that there are cases of collapsed bridges with higher spans resulting in no casualties at all. The data is too limited, and too susceptible to outliers, for such an argument to be supported by statistical evidence. This however does not imply that it is unreasonable to link the potential number of casualties to bridge span in risk-based assessments.

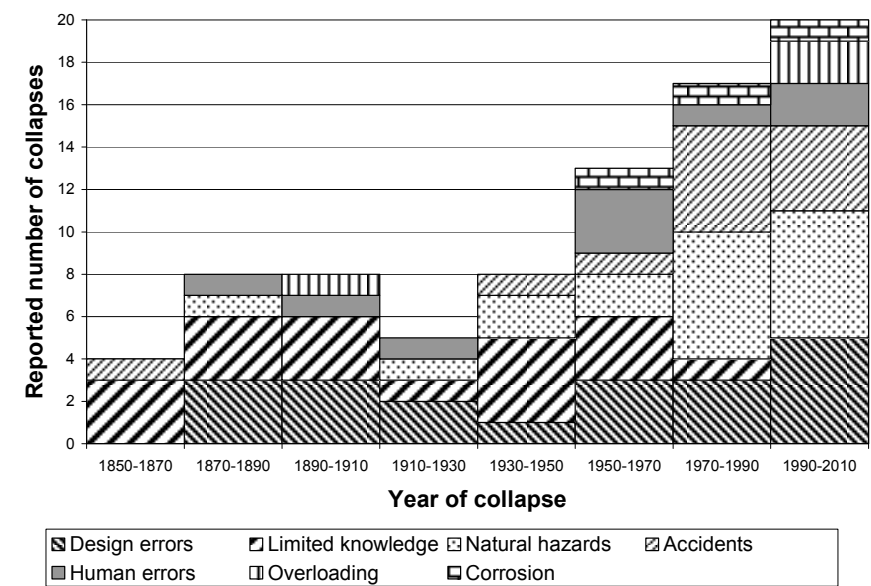

Figure 5. Histogram showing reported collapses with respect to year of collapse and contribution of each failure cause.

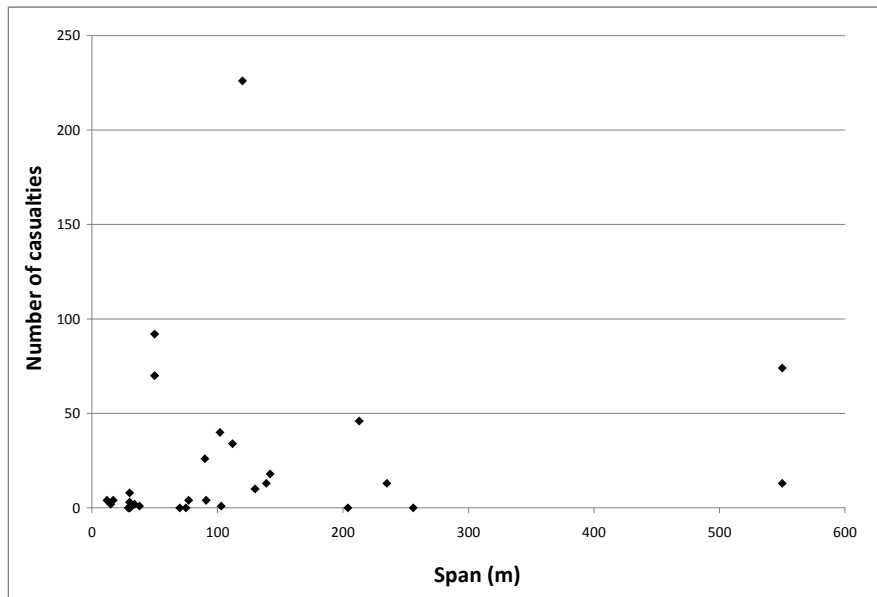

Figure 6. Number of casualties versus collapsed span for metallic bridges.

\subsection{Non-collapsed bridges}

The distribution of failure modes for the 73 noncollapsed bridge cases is shown in Figure 7. It can be seen that the dominant mode is fatigue $(67 \%)$, followed by impact $(10 \%)$ and fracture $(5 \%)$. Once more, for $12 \%$ of cases the failure modes have not been reported in sufficient detail. The fact that such a high number of fatigue failures are in this category indicates the attention paid to the phenomenon by bridge engineers. It also suggests that fatigue failure is, more often than not, picked up at an early enough stage through inspections (and/or that the level of redundancy in metallic bridges with respect to fatigue detail failure is satisfactory) so that it does not result in collapse.

The high percentage of fatigue problems shown in Figure 7 may, in part, be attributed to the fact that these problems seem to be over-reported, especially for welded bridges constructed in the period 19501980. There is a wide range of available data in the literature, in the form of case studies, regarding fatigue cracking of metallic bridges (see, for example, Fisher 1984). For that reason, the causes resulting in fatigue cracking were investigated in more detail and a breakdown of these is shown in Figure 8. It can be seen that the majority of the fatigue cracking observed is attributed to out-of-plane distortions in welded structures (29\%), unanticipated connection fixity and secondary stresses in riveted structures $(27 \%)$, and poor quality material/welding (20\%). The former two are conditions that were not accounted for explicitly during the design of the bridges. It is evident that fatigue is still an area of concern, and needs to be further researched both on a local and global level.

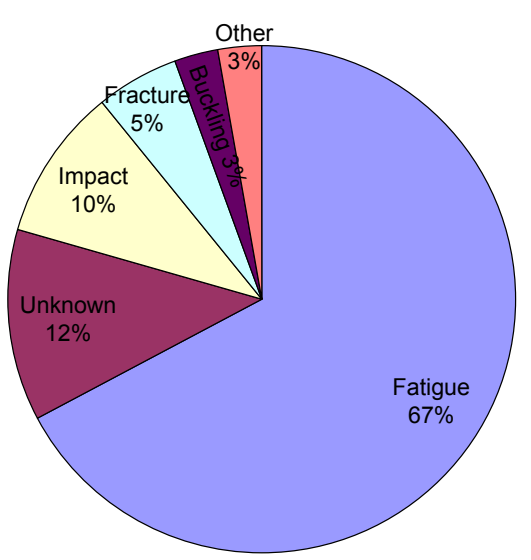

Figure 7. Failure modes for non-collapsed metallic bridges.

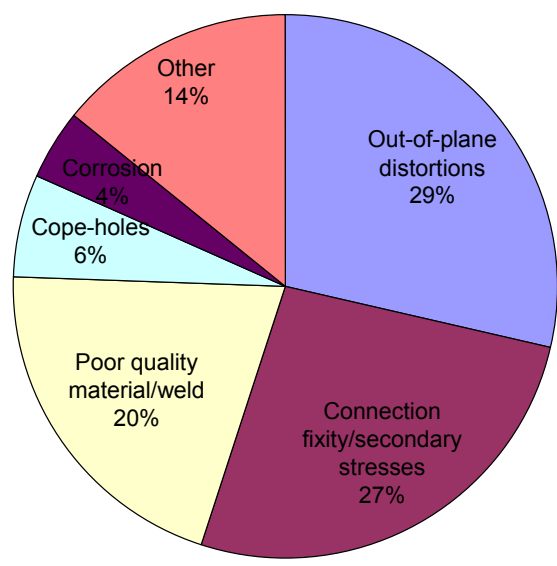

Figure 8. Nature of fatigue cracking in non-collapsed metallic bridges. 
The distribution with respect to the structural form of the bridges for the cases defined as nocollapse is shown in Figure 9. As can be seen, the majority are girder bridges (40\%) and truss bridges $(29 \%)$ followed by a smaller percentage of arch $(10 \%)$ and lattice girder $(8 \%)$ bridges. This is in contrast to the statistics observed for the set of collapsed bridges where the majority were truss bridges followed by girder bridges (see Fig. 3). Arguably, failures can be detected more promptly in girder bridges and/or the redundancy of such bridges is higher, thus preventing total bridge collapse.

From further processing of the data pertaining to non-collapsed metallic bridges, some interesting observations can be summarised as follows:

- $53 \%$ of the fatigue problems were encountered in welded bridges (26 cases) whereas $41 \%$ in riveted bridges (20 cases); again, this would have to seen in the context or relative population sizes, which is not known at present.

- Out of the 29 cases of non-collapsed girder bridges, the vast majority $(86 \%)$ were found to have fatigue problems; 18 of these bridges were of welded construction, which suggests that, fatigue excepted, the design and construction of such bridges is well understood and executed.

- In the case of truss bridges, a smaller percentage of failures was attributed to fatigue (43\%, 9 bridges). Out of these 9 bridges, 7 were of riveted construction, which is perhaps related to the large number of riveted truss bridges across Europe and North America.

- The vast majority of failures in arch bridges $(86 \%)$ were also attributed to fatigue problems.

- All of the lattice-girder bridges (6 cases) had fatigue failures and were all constructed of wrought-iron material (in all probability built around 150 years ago).

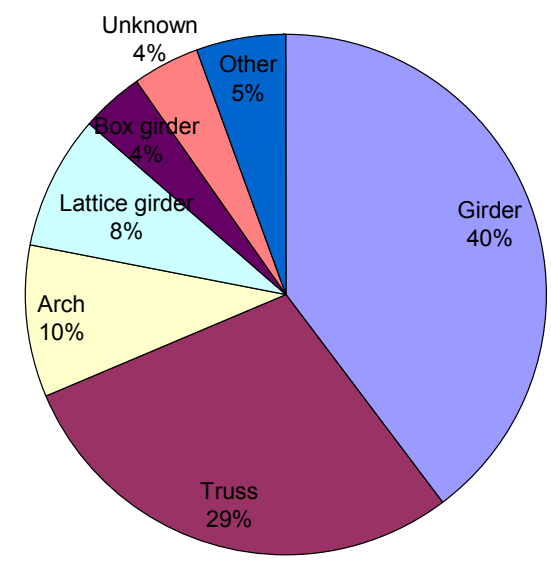

Figure 9. Structural configuration of non-collapsed metallic bridges.

\section{CONSEQUENCES OF FAILURE}

The consequences of failure are a good indicator of the importance of a bridge structure. Considering these consequences is essential in both qualitative and quantitative risk-based design and assessment.

Consequences can generally be divided into direct or indirect. Direct consequences can be associated with possible injuries or fatalities due to the failure as well as with re-construction costs of the bridge, in the case of total collapse, or repair costs, in the case of damage. Indirect consequences, on the other hand, may arise due to loss of functionality of the transportation network following on from the bridge failure and the unavailability of the bridge. These can be associated with traffic disruption and delay costs due to repair works or detour due to complete bridge closure, traffic management costs, social and environmental impact costs etc. In some cases, bridges are not only elements of the transportation infrastructure but they also form part of electricity, telephone, water, gas networks as well (Stimpson 2009). Therefore, the consequences of bridge failures may extend far wider than the boundaries of transportation systems to other forms of critical infrastructure.

Quantification of bridge failure consequences is often challenging since it requires determining the different contributions. It is customary and practical to express consequences in terms of monetary units, though this is rarely easy to do. Difficulties are encountered in expressing loss of life or injuries in monetary units and in quantifying economic, social and possible environmental impacts. The duration over which a bridge might be unavailable is perhaps more uncertain than the replacement cost itself, and this is one reason why indirect costs are subject to higher levels of uncertainty and ambiguity with respect to the definition of appropriate system boundaries. Nevertheless, there have already been attempts to develop models for the estimation of consequences of bridge failures (Imhof 2004; Wong et al. 2005; Stein \& Sedmera 2006), and more is likely to appear from both researchers and practitioners in the near future, due to a number of drivers, such as infrastructure inter-dependency, urbanisation and climate change adaptation.

There have been bridge collapses in the past that have resulted in significant impact not only in terms of direct financial costs but also in terms of wider implications to the engineering profession and large indirect costs. A failure of a bridge due to an inherent lack of understanding in design may mean the strengthening or replacement of a whole class of structures, each designed according to the same criteria as the one which collapsed. Changes in codes of practices may also need to be introduced following a bridge collapse. A typical example was the introduction of new rules for steel bridges in the Brit- 
ish Standards after the collapse of the Cleddau boxgirder bridge in Milford Haven, UK and the West Gate bridge in Australia. Another example is the collapse of the Tacoma Narrows bridge in the USA which resulted in immediate retrofit of a number of similar bridges, with large associated costs, and led to significant research into the dynamic effects of wind on bridges and the development of new design rules.

A recent example of the significance of indirect consequences of failure is the case of the I-35W bridge collapse in Minneapolis in 2007. The direct consequences of the failure of the bridge were $13 \mathrm{fa}$ talities and 145 injuries and the reconstruction cost of the bridge, which was estimated around \$234 million. The cost of disruption and re-routing due to the unavailability of the bridge was estimated as $\$ 400,000$ per day (Minnesota Department of Transportation, 2007) which totals to approximately $\$ 150$ million for the duration of the construction of the new bridge. Further analyses estimated the economic impact or loss to Minnesota's economy, at about $\$ 17$ million in 2007 and \$43 million in 2008 (Minnesota Department of Employment and Economic Development, 2007). It is evident in this case that indirect consequences add up close to the level of direct consequences even though the former have only been quantified with respect to only some of the possible factors (e.g. no social or environmental impact or the impact due to reputation loss appear to have been considered).

\section{CONCLUSIONS}

A review of failure statistics for metallic bridges was presented in this paper. Classification of the 164 failure cases with respect to whether they resulted in total collapse or not, causes of failure, failure modes and bridge structural configuration was carried out. The results have shown that design errors, natural hazards and limited knowledge are the primary factors contributing to bridge collapses. However, failures attributed to limited knowledge have been found to become increasingly rare during the last few decades. Scour and buckling failures were found to be the most common collapse modes for metallic bridges whereas fatigue was found to be the most common failure mode in the case of non-collapsed (damaged) metallic bridges. The statistics have also shown that truss bridges are more susceptible to total collapse failures and girder bridges to failures that do not necessarily result in total collapse. Overall, incidents attributed to natural hazards and accidents show an increasing trend in recent years, with design and human errors remaining remarkably constant in percentage terms during the investigated 150-year period.
Bridge failures suggest that there is still a clear need for risk assessment of structures, both in service and during construction. Risks of structures in service should be examined to determine more appropriate assessment, inspection and strengthening/repair criteria, especially in order to account for external extreme events such as natural hazards, vehicle impacts and other forms of accidents. Risk analyses during the construction stage will aid in selecting methods and procedures that have higher notional reliability and to introduce controls that will prevent failures. As suggested in recent SCOSS reports, utilising the '3Ps', pertaining to people, process and product, can help describe and categorise the contributory factors which may lead to failure. The '3Ps', emphasise the wide range of influences in designing and constructing structures, and ensure that 'human factors' are a key component of any risk assessment (SCOSS, 2007).

\section{ACKNOWLEDGEMENTS}

The work described in this paper forms part of the European project COST601: Robustness of structures. Helpful discussions with the participants are gratefully acknowledged.

\section{REFERENCES}

Akesson, B. 2008. Understanding bridge collapses. London: Taylor \& Francis

Biezma, M.V. \& Schanack, F. 2007. Collapse of Steel Bridges. Journal of Performance of Constructed Facilities (ASCE) 21(5): 398-405.

Blockley, D.I. 1976. Analysis of structural failures. Proceedings of the Institution of Civil Engineers, 62: 51-74.

BridgeForum. 2009. Bridge collapse database. University of Cambridge, UK.(http://www.bridgeforum.org/dir/collapse/)

Collins, D. 2008. Lessons from historical bridge failures. Proceedings of the Institution of Civil Engineers, Civil Engineering 161: 20-27.

Eldukair, Z.A. \& Ayyub, B.M. 1991. Analysis of recent U.S. structural and construction failures. Journal of Performance of Constructed Facilities (ASCE) 5(1): 57-73.

Ellingwood, B. 1987. Design and construction error effects on structural reliability. Journal of Structural Engineering (ASCE) 113(2): 409-421.

Feld, J. \& Carper, K.L. 1997. Construction failure. New York: Wiley.

Fisher, J.W. 1984. Fatigue and fracture in steel bridges: Case studies. New York: Wiley.

Hadipriono, F.C. 1985. Analysis of events in recent structural failures. Journal of Structural Engineering (ASCE) 111(7): 1468-1481.

Hadipriono, F.C. \& Diaz, C.F. 1988. Trends in recent construction and structural failures in the United States. Forensic Engineering 1(4): 227-232.

Harik, I.E., Shaaban, A.M., Gesund, H., Valli, Y.S., Wang, S.T. 1990. United States bridge failures, 1951-1988. Journal of Performance of Constructed Facilities (ASCE) 4(4): 272-277. 
Imhof, D. 2004. Risk assessment of existing bridge structures. PhD Thesis. University of Cambridge, UK.

JBA Consulting. 2004. Scour and flood risk at railway structures. Final report prepared for Railway Safety \& Standards Board, Project No. T112, Skipton, North Yorkshire, UK.

Minnesota Department of Transportation. 2007. Road user cost due unavailability of Interstate $35 \mathrm{~W}$ Mississippi river crossing at Minneapolis, Minnesota. Technical report, Office of Investment Management.

Minnesota Department of Employment and Economic Development. 2007. Economic impacts of the I-35W bridge collapse.

Nowak, A.S. 1979. Effect of human errors on structural safety. Journal of the American Concrete Institute, 959-972.

Nowak, A.S. \& Carr, R.I. 1985. Sensitivity analysis for structural errors. Journal of Structural Engineering (ASCE) 111(8): 1734-1746.

Pugsley, A.G. 1973. The prediction of proneness to structural accidents. Structural Engineer 51: 195-196.

Reed, D.W. 2004. A review of British railway bridge flood failures. In Hydrology: Science \& Practice for the $21^{\text {st }} \mathrm{Cen}$ tury, Volume I: 210-216.

Ross, S.S. 1984. Construction disasters: Design failures, causes, and prevention. London: McGraw-Hill.

SCOSS. 2007. The Standing Committee on Structural Safety, $16^{\text {th }}$ Biennial Report, London.

Silby, P.G. \& Walker, A.C. 1977. Structural accidents and their causes. Proceedings of the Institution of Civil Engineers, Part 1, 62: 191-208.

Smith, D.W. 1976. Bridge failures. Proceedings of the Institution of Civil Engineers, Part 1, 60: 367-382.

Stein, S. \& Sedmera, K. 2006. Risk-Based Management Guidelines for Scour at Bridges with Unknown Foundations. NCHRP Web-Only Document 107, National Cooperative Highway Research Program, Transportation Research Board.

Stimpson, J. 2009. Cumbria flooding exposes UK's vulnerability to infrastructure failure. New Civil Engineer. (http:// www.nce.co.uk/home/water/cumbria-flooding-exposesuks-vulnerability-to-infrastructure-failure/5211340.article)

Wardhana, K. \& Hadipriono, F.C. 2003. Analysis of Recent Bridge Failures in the United States. Journal of Performance of Constructed Facilities (ASCE) 17(3): 144-150.

Wong, S.M., Onof, C.J., Hobbs, R.E. 2005. Models for evaluating the costs of bridge failure. Proceedings of the Institution of Civil Engineers, Bridge Engineering 158(BE3): 117-128. 